\title{
Propriedades físico-hídricas em Latossolo do Cerrado sob diferentes sistemas de manejo
}

\author{
Cícero C. de Figueiredo ${ }^{1}$, Glenio G. Santos ${ }^{1}$, Sidney Pereira ${ }^{1}$, Jorge L. do Nascimento ${ }^{1}$ \& José Alves Júnior ${ }^{1}$
}

\section{RESUMO}

Visou-se, neste trabalho, avaliar as propriedades físico-hídricas do solo sob diferentes sistemas de manejo, em comparação com o Cerrado nativo, em Santo Antônio de Goiás, GO, em áreas cultivadas desde o ano de 1993. As propriedades físico-hídricas foram avaliadas nas profundidades de 0-0,10 e 0,10-0,20 m do solo submetido aos sistemas de manejo: S1 (soja/feijão/arroz/milheto/feijão), S2 (soja/milheto/milho), S3 (milho + pastagem de braquiária - integração-lavoura-pecuária) e S4 (cerrado nativo). Utilizou-se, para comparar os resultados obtidos nos diversos sistemas de manejo do solo, o intervalo de confiança com nível de probabilidade de 5\%. A área com pastagem de braquiária sob pastejo animal promoveu compactação do solo na camada superficial, verificada pela redução da macroporosidade, aumento da microporosidade e da densidade do solo.

Palavras-chave: rotação de culturas, densidade do solo, porosidade do solo, retenção de água

\section{Physico-hydric properties of Cerrado Latosol under different management systems}

\begin{abstract}
The objective of this study was to evaluate the physico-hydric soil properties under different management systems in comparison with the native Cerrado, in Santo Antônio de Goiás, Goiás State, in areas cultivated since 1993. The evaluated systems in the depths of $0-0.10$ and $0.10-0.20 \mathrm{~m}$ were: system S1 (soybean/bean/rice/pearl millet /bean), system S2 (soybean/pearl millet/corn), system S3 (corn + Brachiaria brizantha in integrated crop-livestock system) and system S4 (native cerrado). To compare the results obtained in the several soil management systems, the interval of confidence was used, at a probability level of $5 \%$. The use of area under Brachiaria brizantha pasture for animal grazing caused compaction of the soil in the surface layer, verified through the reduction of the macroporosity, and increase of the microporosity and soil bulk density.
\end{abstract}

Key words: crop rotation, bulk density, soil porosity, water retention 


\section{INTRODUÇÃO}

O uso intensivo da terra para a produção vegetal e animal tem causado degradação da estrutura do solo. A degradação da estrutura afeta negativamente o desenvolvimento vegetal e predispõe o solo a erosão hídrica (Stone \& Guimarães, 2005). A medida em que se intensifica o uso agrícola, as propriedades físicas do solo sofrem alterações, geralmente desfavoráveis ao crescimento vegetal e essas alterações são ainda mais nítidas quando os sistemas de uso do solo são comparados com a vegetação natural de cerrado (Spera et al., 2004).

O solo mantido em estado natural sob vegetação nativa, preserva as características físicas adequadas ao desenvolvimento normal das plantas condições em que o volume de solo explorado pelas raízes é relativamente grande (Andreola et al., 2000). Bertol et al. (2004) estudando as propriedades físicas do solo sob preparo convencional e semeadura direta em rotação e sucessão de culturas comparadas às do campo nativo, concluíram que na camada de $0-0,10 \mathrm{~m}$ a densidade do solo é maior na semeadura direta que no preparo convencional e no campo nativo; nesta camada, a semeadura direta reduziu o volume de macroporos em relação ao preparo convencional e ao campo nativo.

Stone \& Silveira (2001) verificaram que o não revolvimento ocasionou maior compactação da camada superficial do solo sob plantio direto em comparação com os sistemas convencionais de preparo, evidenciado pelo maior valor de densidade do solo e menores de porosidade total e macroporosidade. Esta redução da macroporosidade pode estar associada a um aumento da retenção de água. Silva et al. (2005) notaram que sistemas agrícolas com cana-de-açúcar irrigada e de sequeiro, promoveram aumento na densidade e na porosidade mas aumentaram a retenção e a disponibilidade de água, quando comparados com o solo sob mata nativa.

Na busca por sistemas de manejo que promovam melhoria na estruturação do solo e, conseqüentemente, na retenção e no armazenamento de água, deve-se considerar as culturas utilizadas e a qualidade dos resíduos deixados no solo; neste caso, Stone \& Guimarães (2005) concluíram, nas condições climáticas do Cerrado, que a rotação de arroz com soja e milho ou milheto safrinha propiciou melhor qualidade física do solo em relação às demais rotações, especialmente quando o milho foi usado na safrinha. Ainda de acordo com os autores, a melhoria dos atributos físicos se deve ao maior aporte de matéria orgânica ao solo.

Também em estudo no Cerrado, Stone \& Silveira (2001) notaram que os sistemas de rotação de culturas, que incluíram soja e trigo, provocaram maior compactação da camada superficial do solo enquanto o sistema arroz consorciado com calopogônio-feijão propiciou maior valor de macroporosidade e menor de microporosidade.

As áreas sob pastagem bem manejadas também se apresentam como alternativa importante na melhoria das condições físico-hídricas dos solos. Moreira et al. (2005) verificaram melhores condições físicas relacionadas à porosidade, à densidade e à resistência à penetração em solos sob pastagens manejadas, quando comparadas com pastagens degradadas.
Apesar dos avanços tecnológicos e da implantação de sistemas agrícolas sustentáveis, como plantio direto e integração lavoura-pecuária, ainda é comum o desconhecimento, pelo produtor, dos reais benefícios que a rotação de culturas e o manejo dos solos podem proporcionar.

Objetivou-se, neste trabalho, avaliar propriedades físicohídricas do solo sob diferentes sistemas de manejo em comparação com o Cerrado nativo.

\section{MATERIAL E MÉTODOS}

O estudo foi realizado na área experimental da Embrapa Arroz e Feijão na Fazenda Capivara, em Santo Antônio de Goiás, GO, cujas coordenadas geográficas são: latitude $16^{\circ} 28^{\prime} 00^{\prime}$ S, longitude $49^{\circ} 17^{\prime} 00^{\prime}$ ' W e altitude de $823 \mathrm{~m}$. O solo predominante é o Latossolo Vermelho distroférrico, textura argilosa com relevo plano. A vegetação natural é do tipo cerradão subperenifólio. O clima, conforme classificação de Köppen, é Aw, tropical de savana, megatérmico. A temperatura média anual do ar é de $22,6{ }^{\circ} \mathrm{C}$; e o mês de junho apresenta a menor média de temperatura mínima do ar $\left(14,2^{\circ} \mathrm{C}\right)$, enquanto o mês de setembro mostra a maior média de temperatura máxima do ar $\left(31,4^{\circ} \mathrm{C}\right)$ (Santos, 2007).

Os estudos foram realizados em três áreas de 13,5 ha cada uma, sob cultivo intensivo de lavouras com diferentes rotações de culturas (Tabela 1) e em uma área de cerrado nativo (S4).

Tabela 1. Histórico de cultivo das áreas estudadas - 2005 a 2007

\begin{tabular}{|c|c|c|c|c|c|}
\hline \multirow[b]{2}{*}{ Sistema } & \multicolumn{4}{|c|}{ Safra } & \multirow[b]{2}{*}{$\begin{array}{l}\text { Sistema de } \\
\text { manejo }\end{array}$} \\
\hline & $\begin{array}{c}\text { Verão } \\
\text { 2005-2006 }\end{array}$ & $\begin{array}{c}\text { Inverno } \\
2006\end{array}$ & $\begin{array}{c}\text { Verão } \\
\text { 2006-2007 }\end{array}$ & $\begin{array}{c}\text { Inverno } \\
2007\end{array}$ & \\
\hline$S 1^{(1)}$ & Soja & Feijão & Arroz & $\begin{array}{l}\text { Milheto e } \\
\text { feijão }\end{array}$ & $\begin{array}{c}\text { Preparo } \\
\text { Convencional }\end{array}$ \\
\hline $\mathrm{S} 2^{(2)}$ & Soja & Milheto & Milho & - & Plantio Direto \\
\hline $\mathrm{S} 3^{(3)}$ & $\begin{array}{c}\text { Milho + } \\
\text { braquiária }\end{array}$ & braquiária & braquiária & braquiária & Plantio Direto \\
\hline
\end{tabular}

(1) S1: seqüência de culturas: soja/feijão/arroz/milheto/feijão; (2) S2 seqüência de culturas: soja/ milheto/milho; (3) S2: seqüência de culturas: milho + braquiária/braquiária

No sistema S1, o milheto foi semeado em janeiro de 2007, logo após preparo convencional, sem adubação de plantio e sem adubação de cobertura, em que o principal objetivo da cultura é a formação de palhada para posterior plantio de feijão; no sistema S2, o milho foi semeado em novembro de 2006, sob plantio direto, com adubação de plantio de $400 \mathrm{~kg} \mathrm{ha}^{-1}$ do formulado 05-30-15+Zn e, após 14 e 28 dias, recebeu adubação nitrogenada em cobertura (uréia agrícola) na dosagem de $300 \mathrm{~kg} \mathrm{ha}^{-1}$, dividida em duas aplicações; já no sistema S3 a pastagem de braquiária foi implantada em consórcio com milho, no verão de 2005, em que o primeiro pastejo animal foi realizado no mês de maio de 2006.

A amostragem de solo foi realizada nos dias 16 e 17 de maior de 2007. Determinou-se a densidade do solo pelo método do anel volumétrico utilizando-se amostras de solo com estrutura indeformada, coletadas em anéis volumétricos de $98,0 \mathrm{~cm}^{3}$ (EMBRAPA, 1997). A porosidade total (PT) ou 
volume total de poros expresso em $\mathrm{m}^{3} \mathrm{~m}^{-3}$, foi calculado mediante a Eq. 1.

$$
\mathrm{PT}=1-\left(\frac{\mathrm{D}_{\mathrm{S}}}{\mathrm{D}_{\mathrm{P}}}\right)
$$

em que: $\mathrm{D}_{\mathrm{P}}$ é a densidade de partículas do solo e $\mathrm{D}_{\mathrm{S}}$ é a densidade do solo, ambas expressas em $\mathrm{Mg} \mathrm{m}^{-3}$.

Considerou-se microporosidade do solo o espaço poroso ocupado por água correspondente à tensão de $6 \mathrm{kPa}$, obtida na determinação da curva de retenção de água no solo. Obteve-se a macroporosidade pela diferença entre a porosidade total e a microporosidade, conforme EMBRAPA (1997).

As amostras deformadas nas mesmas profundidades das indeformadas, foram coletadas para determinação da densidade de partículas; utilizou-se, nesta determinação, o método do balão volumétrico (EMBRAPA, 1997).

O emprego do método da centrífuga para obtenção das curvas de retenção de água foi de grande valia, de acordo com Freitas Jr. \& Silva (1984). As amostras não deformadas, utilizadas na determinação da curva de retenção de água, foram previamente saturadas durante $24 \mathrm{~h}$ e submetidas a rotações variadas da centrífuga, pelo tempo de $30 \mathrm{~min}$, com vista à determinação dos diferentes pontos da curva, correspondentes às tensões de 6, 8, 10, 33, 60, 100 e $1.500 \mathrm{kPa}$. Cada valor da rotação, utilizado na centrífuga, corresponde a uma tensão aplicada à amostra, podendo o método de cálculo para a rotação adequada ser encontrado em Freitas Júnior \& Silva (1984).

A curva de retenção de água no solo foi ajustada à equação de van Genuchten (1980), através do programa SWRC - Soil Water Retention Curve (Dourado Neto et al., 2001), dada pela Eq. 2.

$$
\theta(\psi)=\theta_{\mathrm{r}}+\left(\theta_{\mathrm{s}}-\theta_{\mathrm{r}}\right)\left[1+(\alpha \cdot \psi)^{\mathrm{n}}\right]^{-\mathrm{m}}
$$

em que:

$$
\begin{aligned}
& \theta \text { - umidade do solo }\left(\mathrm{m}^{3} \mathrm{~m}^{-3}\right) \\
& \theta_{\mathrm{r}} \text { - umidade residual }\left(\mathrm{m}^{3} \mathrm{~m}^{-3}\right) \text { determinada na ten- } \\
& \quad \text { são de } 1.500 \mathrm{kPa} \\
& \theta_{\mathrm{s}} \text { - umidade de saturação }\left(\mathrm{m}^{3} \mathrm{~m}^{-3}\right) \\
& \psi \text { - potencial mátrico }(\mathrm{kPa}) \mathrm{e}
\end{aligned}
$$

$\alpha, \mathrm{m}, \mathrm{n}-$ valores empíricos da equação

Para comparação dos resultados obtidos nos diversos sistemas de manejo do solo, empregou-se o intervalo de confiança para a média m, com nível de probabilidade de 5\%; este intervalo determina uma faixa de valores estabelecida por um limite inferior (LI) e por um limite superior (LS).

$\mathrm{O}$ intervalo de confiança para a média $\mathrm{m}$ da variável $\mathrm{X}$ em estudo com nível de confiança 1-a, foi calculado com a Eq. 3 (Ribeiro Júnior, 2004).

$$
\operatorname{IC}(\mu)_{1-\alpha}: \bar{X} \pm t_{\alpha / 2} \frac{s_{x}}{\sqrt{n}}
$$

em que:

$$
\mathrm{s}_{\mathrm{x}} \text { - desvio-padrão da amostra }
$$$$
\alpha \text { - nível de significância }
$$
$\mathrm{t}_{\alpha / 2}$ - valor tabelado de " $\mathrm{t}$ ” a nível $\alpha$ com $\mathrm{n}-1$ graus
de liberdade.

\section{RESULTADOS E DISCUSSÃO}

As áreas cultivadas (S1, S2 e S3) e o cerrado nativo (S4) não apresentaram diferenças entre si (intervalo de confiança de 5\%) para densidade de partículas nas profundidades amostradas de 0-0,10 e 0,10-0,20 m (Figura 1A). Esses resultados eram esperados já que, de acordo com Brady (1989), a densidade de partículas depende da natureza do material mineral predominante apresentando, portanto, pouca ou nenhuma diferença para a mesma classe de solo.

A densidade do solo apresentou-se maior para as três áreas sob cultivo em relação ao Cerrado nativo, em que o sistema S3 apresentou, na profundidade de 0-0,10 m, maiores valores de densidade do solo. Para S1 e S2 não se constataram diferenças (intervalo de confiança de $5 \%$ ) entre as profundidades de 0-0,10 m e 0,10-0,20 m (Figura 1B).

As maiores densidades do solo para a profundidade de 0-0,10 m, verificadas em ordem decrescente nos sistemas S3, S2 e S1, respectivamente, demonstram que o pisoteio animal e os cultivos intensivos, mesmo quando há rotação de culturas, tendem a um desarranjo maior das partículas do solo, o que pode comprometer a porosidade e diminuir a infiltração e a redistribuição de água no solo e, como conseqüência, aumentar a compactação, o que prejudicaria sensivelmente a produção agrícola. A maior densidade do solo em 0-0,10 m de profundidade no sistema S3 em relação a todas as profundidades avaliadas dos demais sistemas, manifesta a ação direta do pisoteio animal, cujos resultados estão de acordo com os apresentados por Araújo et al. (2004); os autores estudaram propriedades físicas em Argissolo sob diferentes tipos de uso e verificaram maiores densidades do solo no horizonte superficial em pastagem $\left(1,73 \mathrm{~kg} \mathrm{dm}^{-3}\right)$ e atribuíram esta maior densidade em decorrência do pisoteio animal e da maior predisposição a ciclos de umedecimento e secagem em relação à mata nativa, de acordo, portanto, com os resultados encontrados neste trabalho. Marchão et al. (2007), estudando a qualidade física de Latossolo em sistema de integração lavoura-pecuária no Cerrado, constataram maiores densidades de solo na camada de 0-0,05 m em área de braquiária associada com soja sob plantio direto, demonstrando o efeito da compactação da camada superficial do solo e verificaram que, diferentemente do que ocorreu na pastagem, no sistema plantio convencional de soja durante quatro anos a densidade do solo aumentou em profundidade e este resultado foi atribuído à compactação da subsuperfície, durante a aração do solo para implantação da cultura.

Em relação à profundidade de 0,10-0,20 m, a área sob o sistema S2 indicou maior densidade do solo quanto aos demais sistemas, apresentando significância apenas em relação ao Cerrado nativo; este maior valor de densidade do solo na profundidade de $0,10-0,20 \mathrm{~m}$ na área sob sistema S2 se deve, provavelmente, ao uso intensivo da área, causando entupimento dos poros maiores pelas partículas finas de solo e, conseqüentemente, tendendo à maior compactação do solo 
nesta camada. Oliveira et al. (1996) afirmaram que a expressiva compactação nas camadas subsuperficiais do solo é atribuída ao ajuste de partículas; em conseqüência do entupimento dos poros pelas partículas mais finas e dos ciclos de umedecimento e secagem do solo.

A área sob Cerrado nativo apresentou valores de porosidade total e macroporosidade superiores nas duas profundidades avaliadas, em relação às áreas cultivadas. O sistema S2 mostrou maior macroporosidade para a profundidade de 0-0,10 m em relação ao sistema S3 (Figura 1D); a maior quantidade de microporos foi constatada na área sob S3, não sendo significativa nos demais sistemas avaliados (Figura 1E). O menor e o maior valor de macro e microporos verificados, respectivamente, na camada superficial da área sob S3, estão bastante ligados à maior densidade do solo apresentada para o sistema pastagem, reforçando a hipótese de maior compactação provocada pelos animais durante o pastejo.

Marchão et al. (2007) notaram que a macroporosidade e a porosidade total em áreas sob integração lavoura-pecuária, foram reduzidas quando comparadas com solos sob Cerrado e que esta redução foi da ordem de até 80 e $20 \%$, respectivamente, havendo aumento da microporosidade do solo, confirmando os resultados deste estudo. Stone et al. (2002), avaliando a compactação do solo na cultura do feijoeiro em Latossolo, concluíram que a porosidade total e a macroporosidade diminuíram linearmente e a resistência do solo a penetração aumentou de maneira quadrática com o aumento da densidade do solo. Silva et al. (2005) comparando efeito de sistemas de uso e manejo nas propriedades físico-hídricas em Argissolo, afirmaram que os sistemas de manejo com cana-de-açúcar influenciaram as propriedades físicas do solo, resultando em aumento da densidade com conseqüente redução do volume de mega e macroporos e aumento dos micro e criptoporos, em relação ao solo da mata.

As curvas de retenção de água no solo nas profundidades de 0,0-0,10 e 0,10-0,20 m, para os diferentes sistemas analisados, são apresentadas nas Figuras 2A e 2B, respectivamente. Nas duas profundidades analisadas o cerrado apresentou menores conteúdos de água em todas as tensões analisadas que os demais sistemas; esta baixa capacidade de retenção de água no solo sob cerrado nativo se deve à menor densidade do solo, conferindo maior porosidade total e macroporosidade, influenciando positivamente a condutividade hidráulica, a infiltração e a redistribuição de água no perfil do solo, de forma mais uniforme, conferindo maior aeração do solo, manutenção ou melhoria do ambiente para os organismos edáficos, redução da erosão hídrica e outros.

Sob o sistema S3 na camada de $0,0-0,10 \mathrm{~m}$, o solo apresentou maiores valores de retenção de água em todas as tensões analisadas; esta constatação pode ser justificada pelas maiores quantidades de microporos encontrados nesta camada, no presente sistema.

Stone et al. (1994) constataram, após sete cultivos sucessivos de arroz e feijão em Latossolo do Cerrado, redução na porosidade total, na condutividade hidráulica saturada e na água disponível, além de aumento na densidade do solo e na retenção de água a dado potencial matricial, nas camadas de 0-0,20 e 0,20-0,40 m de profundidade do solo. Silva

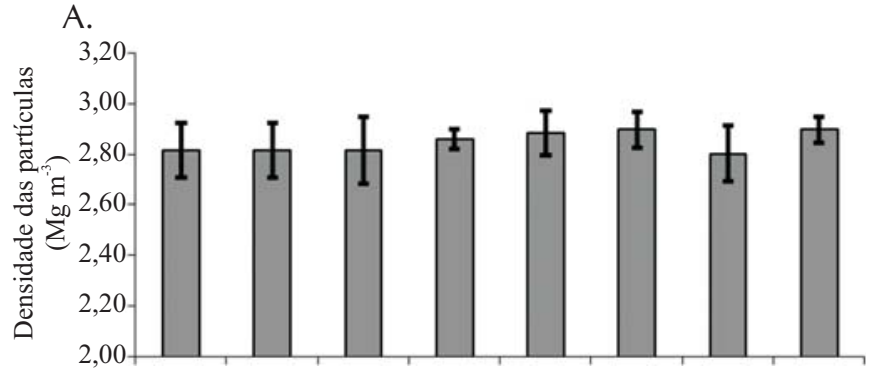

B.

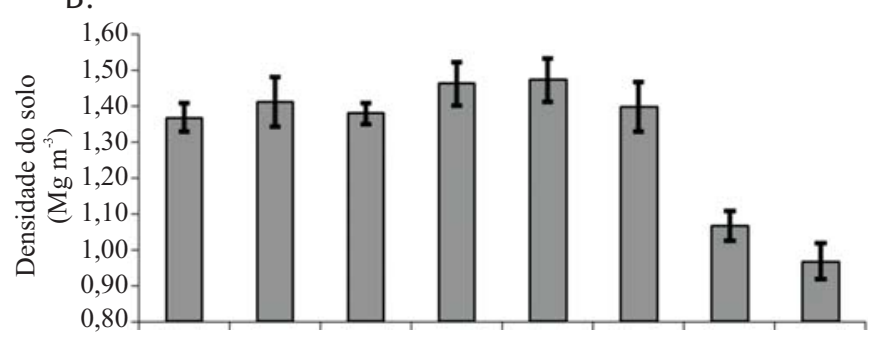

C.

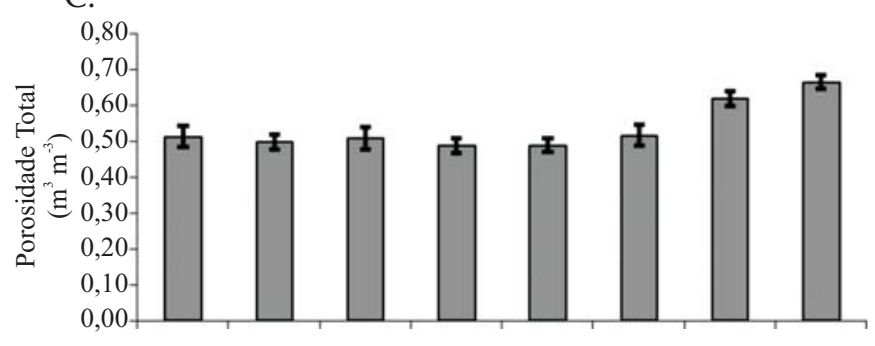

D.

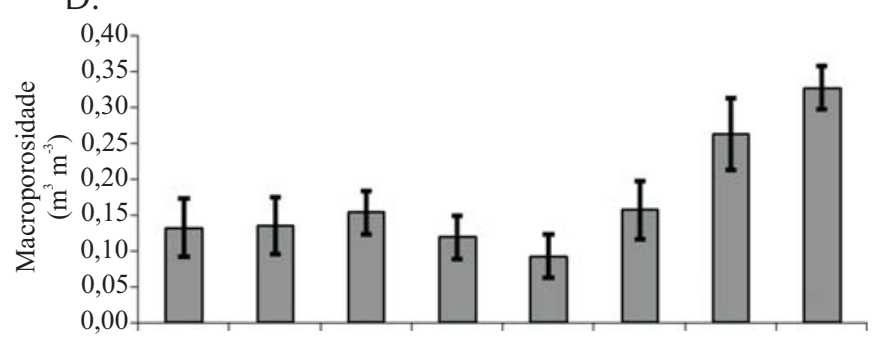

E.

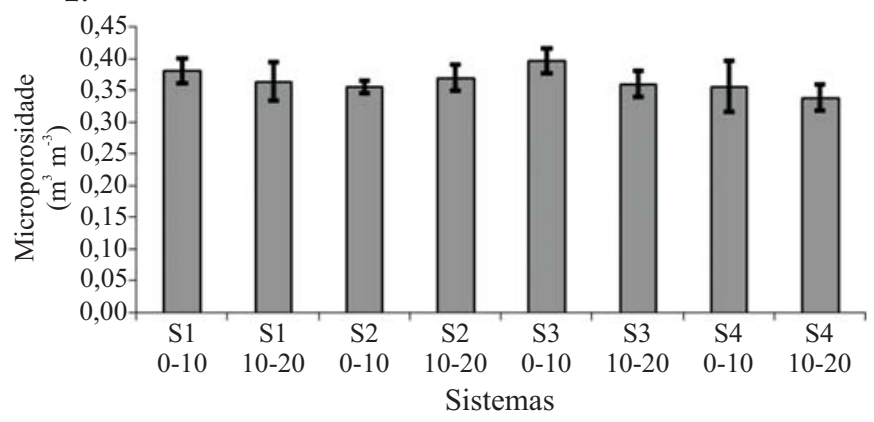

Figura 1. Densidade das partículas (A); Densidade do solo (B); Porosidade total (C); Macroporosidade (d) e Microporosidade (E) do solo nas profundidades amostradas de $0-0,10$ e 0,10-0,20 m. S1: soja/feijão/arroz/ milheto/feijão; S2: soja/milheto/milho; S2: milho + braquiária/braquiária; S4: cerrado nativo. Intervalo de Confiança de 5\%

et al. (2005) verificaram que as alterações na distribuição de diâmetro dos poros promoveram redução da condutividade hidráulica saturada e aumento da retenção de água do solo disponível para as plantas. 


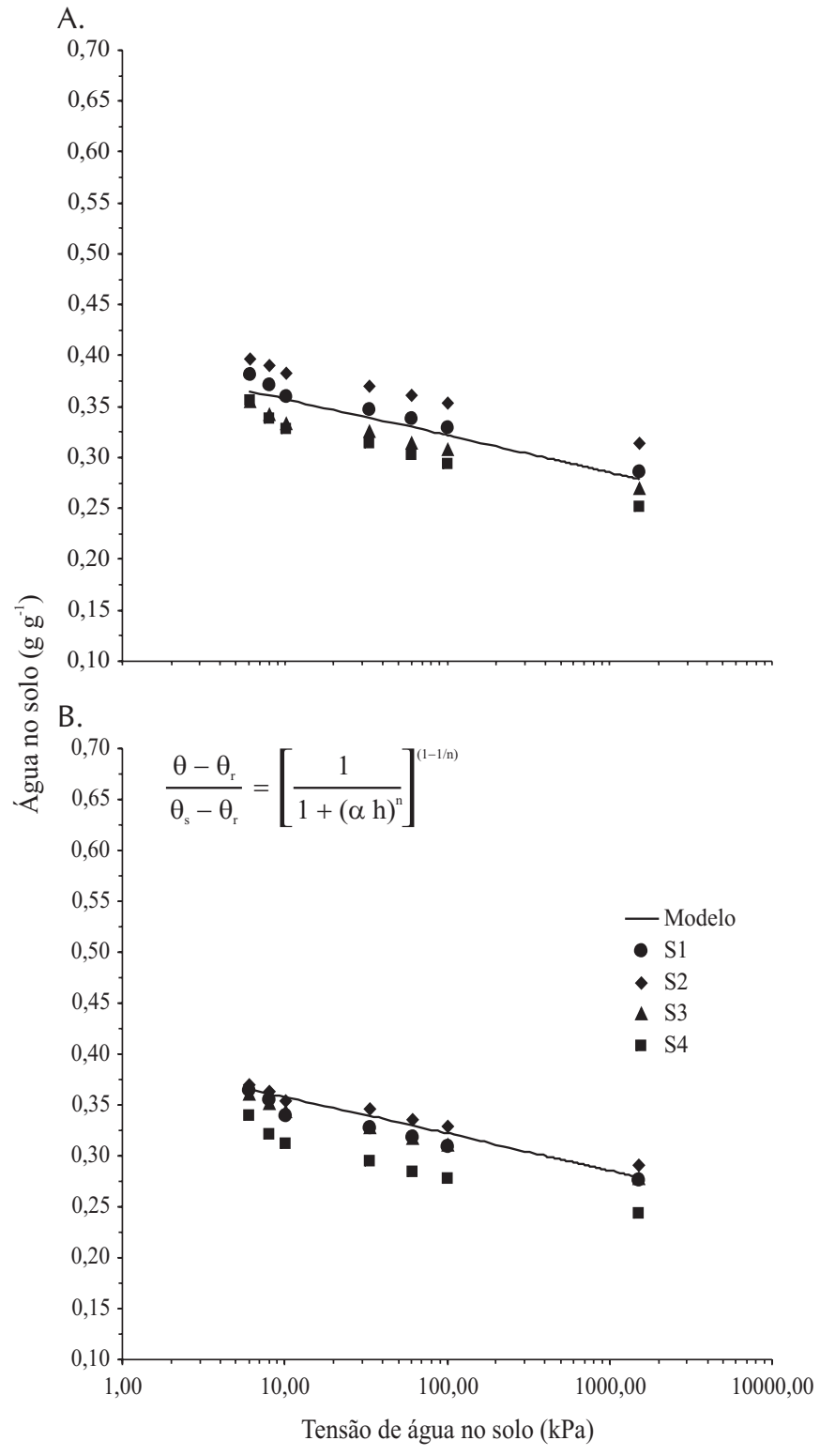

Figura 2. Retenção de água no solo na camada de $0,0-0,10 \mathrm{~m}$ de profundidade (A) e na camada de 0,10 - 0,20 m de profundidade (B) para os sistemas de uso do solo. S1: soja/feijão/arroz/milheto/feijão; S2: soja/ milheto/milho; S2: milho + braquiária/braquiária; S4: cerrado nativo

\section{CONCLUSÕES}

1. Os diferentes sistemas de manejo proporcionaram alterações nas propriedades físico-hídricas do solo, em comparação com a área preservada.

2. A utilização de área sob pastagem de braquiária para pastejo animal promoveu compactação do solo na camada superficial, verificada pela redução da macroporosidade, aumento da microporosidade e densidade do solo.

3. A transformação do Cerrado nativo em sistemas de uso intensivo possibilitou aumento da retenção de água no solo.

\section{AGRADECIMENTOS}

Ao Dr. Pedro Marques da Silveira, pela disponibilização da área experimental, e ao técnico de laboratório Adilson Vilela, pelo apoio nas análises laboratoriais, ambos da Embrapa Arroz e Feijão.

\section{LITERATURA CITADA}

Andreola, F.; Costa, L. M.; Olszevski, N.; Jucksch, I. A cobertura vegetal de inverno e a adubação orgânica e, ou, mineral influenciando a sucessão feijão/milho. Revista Brasileira de Ciência do Solo, v.24, n.4, p.867-874, 2000.

Araújo, E. A.; Lani, J. L.; Amaral, E. F.; Guerra, A. Uso da terra e propriedade físicas e químicas de Argissolo Amarelo distrófico na Amazônia Ocidental. Revista Brasileira de Ciência do Solo, v.28, n.2, p.307-315, 2004.

Bertol, I.; Albuquerque, J. A.; Leite, D.; Amaral, A. J.; Zoldan Júnior, W. A. Propriedades físicas do solo sob preparo convencional e semeadura direta em rotação e sucessão de culturas comparadas às do campo nativo. Revista Brasileira de Ciência do Solo, v.28, n.1, p.155-163, 2004.

Brady, N. C. Natureza e propriedades dos solos. 7.ed. Rio de Janeiro: Freitas Bastos, 1989. 878p.

Dourado Neto, D.; Nielsen, D. R.; Hopmans, J. W.; Reichardt, K.; Bacchi, O. O. S.; Lopes, P. P. Programa para confecção da curva de retenção de água no solo, modelo van Genuchten. Soil water retention curve, SWRC (version 3,00 beta). Piracicaba: USP, 2001.

EMBRAPA - Empresa Brasileira de Pesquisa Agropecuária. Centro Nacional de Pesquisa de Solos. Manual de métodos de análise de solos. 2.ed. Rio de Janeiro: Embrapa CNPS, 1997. 212p. Documentos, 1

Freitas Jr., E.; Silva, E. M. Uso da centrífuga para a determinação da curva de retenção de água no solo, em uma única operação. Pesquisa Agropecuária Brasileira, v.19, n.11, p.14231428, 1984.

Marchão, R. L.; Balbino, L. C.; Silva, E. M.; Santos Junior, J. D. G.; Sá, M. A. C.; Vilela, L.; Becquer, T. Qualidade física de um Latossolo Vermelho sob sistemas de integração lavoura-pecuária no Cerrado. Pesquisa Agropecuária Brasileira, v.42, n.6, p.873-882, 2007.

Moreira, J. A. A.; Oliveira, I. P.; Guimarães, C. M.; Stone, L. F. Atributos químicos e físicos de um Latossolo Vermelho distrófico sob pastagens recuperada e degradada. Pesquisa Agropecuária Tropical, v.35, n.3, p.155-161, 2005.

Oliveira, T. S.; Costa, L. M.; Figueiredo, M. S.; Regazzi, A. J. Efeitos dos ciclos de umedecimento e secagem sobre a estabilidade de agregados em água de quatro Latossolos Brasileiros. Revista Brasileira de Ciência do Solo, v.20, n.3, p.509-515, 1996.

Ribeiro Jr., J. I. Análises estatísticas no excel: GpráticoViçosa: UFV, 2004. 251p.

Santos, G. G. Efeito de culturas de cobertura em plantio direto sobre a macrofauna, agregados e atributos químicos de um Latossolo do Cerrado. Goiânia: UFG, 2007. 97p. Dissertação Mestrado

Silva, A. J. N.; Cabeda, M. S. V.; Lima, J. F. W. F. Efeito de sistemas de uso e manejo nas propriedades físico-hídricas de um Argissolo Amarelo de tabuleiro costeiro. Revista Brasileira de Ciência do Solo, v.29, n.1, p.833-842, 2005. 
Spera, S. T.; Santos, H. P.; Fontaenli, R. S.; Tomm, G. O. Efeito de sistemas de produção de grãos envolvendo pastagens sob plantio direto nos atributos físicos do solo e sua produtividade. Revista Brasileira de Ciência do Solo, v.28, n.3, p.533-542, 2004.

Stone, L. F.; Guimarães, C. M. Influência de sistemas de rotação de culturas nos atributos físicos do solo. Santo Antonio de Goiás: Embrapa Arroz e Feijão. 2005. 15p. Boletim de Pesquisa e Desenvolvimento. Stone, L. F.; Guimarães, C. M.; Moreira, J. A. A. Compactação do solo na cultura do feijoeiro. I: efeitos nas propriedades físicohídricas do solo. Revista Brasileira de Engenharia Agrícola e Ambiental, v.6, n.2, p.207-212, 2002.
Stone, L. F.; Silveira, P. M. Efeitos do sistema de preparo e da rotação de culturas na porosidade e densidade do solo. Revista Brasileira de Ciência do Solo, v.25, n.2, p.395-401, 2001.

Stone, L. F.; Silveira, P. M.; Zimmermann, F. J. P. Características físico-hídricas e químicas de um Latossolo após adubação e cultivos sucessivos de arroz e feijão, sob irrigação por aspersão. Revista Brasileira de Ciência do Solo, v.18, n.3, p.533-539, 1994.

van Genuchten, M. T. A closed-form equation for predicting the hydraulic conductivity of unsaturated soils. Soil Science Society of America Journal, v.44, p.892-898, 1980. 